\title{
BMJ Open Development and validation of a 21-item challenges to stopping smoking (CSS-21) scale
}

\author{
Dennis Thomas, ${ }^{1}$ Andrew J Mackinnon, ${ }^{2}$ Billie Bonevski, ${ }^{3}$ Michael J Abramson, ${ }^{4}$ \\ Simone Taylor, ${ }^{5}$ Susan G Poole, ${ }^{1,6}$ Gregory R Weeks, ${ }^{1,7}$ Michael J Dooley, ${ }^{1,6}$ \\ Johnson George ${ }^{1}$
}

To cite: Thomas $D$, Mackinnon AJ, Bonevski B, et al. Development and validation of a 21 -item challenges to stopping smoking (CSS-21) scale. BMJ Open 2016;6:e011265. doi:10.1136/bmjopen-2016011265

- Prepublication history and additional material is available. To view please visit the journal (http://dx.doi.org/ 10.1136/bmjopen-2016011265).

Received 23 January 2016 Revised 26 February 2016 Accepted 10 March 2016

For numbered affiliations see end of article.

\section{Correspondence to} Dr Johnson George; Johnson.George@monash. edu

\section{ABSTRACT}

Objective: Identification of challenges associated with quitting and overcoming them may improve cessation outcomes. This study describes the development and initial validation of a scale for measuring challenges to stopping smoking.

Methods: The item pool was generated from empirical and theoretical literature and existing scales, expert opinion and interviews with smokers and ex-smokers. The questionnaire was administered to smokers and recent quitters who participated in a hospital-based smoking cessation trial. Exploratory factor analysis was performed to identify subscales in the questionnaire. Internal consistency, validity and robustness of the subscales were evaluated.

Results: Of a total of 182 participants with a mean age of 55 years (SD 12.8), 128 (70.3\%) were current smokers and $54(29.7 \%)$ ex-smokers. Factor analysis of the 21-item questionnaire resulted in a 2-factor solution representing items measuring intrinsic ( 9 items) and extrinsic (12 items) challenges. This structure was stable in various analyses and the 2 factors accounted for $50.7 \%$ of the total variance of the polychoric correlations between the items. Internal consistency (Cronbach's $\alpha$ ) coefficients for the intrinsic and extrinsic subscales were 0.86 and 0.82 , respectively. Compared with ex-smokers, current smokers had a higher mean score $( \pm S D)$ for intrinsic (24.0 \pm 6.4 vs $20.5 \pm 7.4, p=0.002$ ) and extrinsic subscales $(22.3 \pm 7.5$ vs $18.6 \pm 6.0, p=0.001)$.

Conclusions: Initial evaluation suggests that the 21 . item challenges to stopping smoking scale is a valid and reliable instrument that can be used in research and clinical settings to assess challenges to stopping smoking.

\section{INTRODUCTION}

Tobacco smoking is a leading risk factor for chronic disease and death, including many types of cancer, respiratory conditions and cardiovascular diseases. ${ }^{1}$ The probability of a lifelong smoker dying prematurely from a smoking-related disease is almost $50 \%{ }^{2}$

\section{Strengths and limitations of this study}

- This study explored the reliability, validity and factorial structure of the 21-item challenges to stopping smoking (CSS-21) scale.

- The CSS-21 scale has potential use in clinical practice and research and can be used as a selfadministered or interviewer-administered tool to measure challenges associated with quitting smoking.

- The sample was drawn from hospitalised smokers participating in a smoking cessation trial and hence may not represent the general smoking population.

- The scale requires further validation such as test-retest reliability and predictive validity.

Smoking cessation leads to significant health benefits immediately and also decreases most of the related risks within a few years of cessation. $^{2}$

Most smokers want to quit, ${ }^{3}$ but quitting is difficult, and multiple quit attempts are frequently required before long-term abstinence is achieved. ${ }^{4}$ Over half $(52 \%)$ of the smokers in the USA, ${ }^{3} 30 \%$ in Australia ${ }^{5}$ and $26 \%$ in the $\mathrm{UK}^{6}$ reported unsuccessful attempts to give up smoking in the previous 12 months. Even though smoking is considered a chronic disease, it is largely neglected in clinical practice. ${ }^{7}$ Despite multiple attempts to quit, few smokers use the currently available range of treatment options. ${ }^{8}$ Only $3-5 \%$ of unaided quit attempts are successful $6-12$ months later ${ }^{9}$ and even the best available treatment options produce only 25$30 \%$ success rate. ${ }^{10}$ People smoke for different reasons, and a variety of barriers prevent smokers from quitting. Using a patientcentred treatment approach may improve outcomes. ${ }^{11}$

Social cognitive theory (SCT) explains how individuals acquire and maintain certain 
behavioural patterns. ${ }^{12}{ }^{13}$ It also provides a useful framework for designing, implementing and evaluating health promotion interventions. According to the SCT, behavioural patterns are influenced by environmental and personal factors. ${ }^{12}$ Environment refers to the physical (availability or presence of certain substances) and the social (family members, friends and colleagues) environments. Personal factors may include cognitive, affective and biological elements.

A considerable body of research exists examining challenges to quitting smoking. Personal barriers including withdrawal symptoms, addiction, higher levels of perceived stress and doubting ability to quit are frequently cited in the literature. In addition, environmental factors such as concern about weight gain, poor knowledge and scepticism about the available support, cost of nicotine replacement therapy, lack of support from health professionals, social pressure to smoke and perceived social exclusions after quitting and absence of peer support are also often noted. ${ }^{14-23}$ Most of these findings are from qualitative studies. Few structured and quantitative scales for examining the challenges to quitting exist. ${ }^{24-27}$

In 1995, Macnee and Talsma ${ }^{24}$ developed an inventory to assess barriers to cessation (BCS). Their instrument comprised three subscales measuring addiction, and external and internal barriers to quitting smoking. However, this scale may not reflect current barriers as many aspects, especially tobacco availability, restrictions on tobacco use and treatment options for nicotine, have changed in the past two decades. Many countries have introduced population-wide tobacco control measures and new evidence-based treatments have become available. ${ }^{28}{ }^{29}$ Moreover, smoking has become less acceptable in many societies, which in turn might have changed the environmental factors affecting smoking. Additionally, the BCS scale does not measure some of the specific barriers reported in the recent literature. For example, stress has been identified as a barrier to quitting in many studies, ${ }^{21}$ but it was not captured in the BCS. Likewise, boredom, fear of weight gain, lack of support from health professionals, cost of smoking cessation medications, use of other substances and easy availability of cigarettes were also not included in the BCS. ${ }^{21}$ Other scales assessing barriers have not been validated ${ }^{25-27}$ or do not assess barriers experienced during a quit attempt. $^{3031}$

Identifying various personal and environmental factors affecting smoking behaviour may guide the selection of appropriate smoking cessation support strategies that are more likely to be successful in future attempts, thus ensuring efficient use of clinicians' time and limited healthcare resources. The current study aimed to develop a comprehensive questionnaire to assess personal and environmental factors affecting smoking cessation. We sought to establish the measurement properties of this questionnaire including reliability, and face and construct validity.

\section{MATERIALS AND METHODS}

\section{Construct development}

Item generation

The initial item pool of the questionnaire was based on the 19-item BCS scale. ${ }^{24}$ The SCT framework was used to conceptualise the items. A comprehensive literature review identified personal and environmental factors associated with smoking. The items were reviewed for appropriateness of content by a team of experts (2 smoking cessation researchers and 2 behavioural scientists) and 16 researchers working in public health and health services. In addition, consumer consultation was conducted with 12 smokers and 2 ex-smokers. Consumer consultation involved completion of the questionnaire, followed by a face-to-face interview with a research assistant to identify any additional challenges to quitting smoking and feedback concerning clarity, appropriateness and comprehension of items, and ease and acceptability of instructions and format. Items of the BCS scale were combined or eliminated to avoid redundancy (see online supplementary table S1). A few items were rephrased to improve clarity, and 13 new items were added. The initial inventory derived from these steps included 23 items. A four-point scale was used for recording responses. The scale instructions read 'The following statements refer to different challenges or problems associated with stopping smoking. Please rate how much of a challenge each one of them was in your most recent attempt to stop smoking. Please indicate your responses on a scale of 1 (not a challenge); 2 (minor challenge); 3 (moderate challenge) or 4 (major challenge) by circling the appropriate number for each statement'.

The development sample was also asked to identify any additional challenges for smoking cessation. The responses to this question were reviewed by two investigators (DT and JG) to determine whether those subjective responses should be considered for inclusion in the scale.

\section{Administration of the questionnaire to the validation sample \\ Participants}

Participants were recruited from a randomised controlled trial (RCT) evaluating the effectiveness of a hospitalbased smoking cessation intervention (GIVE UP FOR GOOD; Australian and New Zealand Clinical Trial Registry registration number: ACTRN12612000368831). ${ }^{32}$ Participants were 18 years or older, self-reported current (daily or occasional) smokers at the time of hospital admission and available for 12-month follow-up. Patients who were too ill (physically or mentally) to provide written informed consent or participate in the trial, unable to communicate in English, with a terminal illness, pregnant or already receiving active smoking cessation therapy at the time of hospital admission were excluded.

\section{Procedures}

GIVE UP FOR GOOD participants were informed about the survey during their final follow-up interview at 
12 months after the index hospital admission. All individuals interested in participating in the survey had it mailed to them within 1 month after the final trial interview. A reminder was sent to all non-respondents 2 weeks after the initial mail out.

\section{Analyses}

All analyses were conducted using Statistical Package for Social Sciences (SPSS) (V.20.0; IBM, Armonk, New York, USA) and Mplus (V.7.2; Los Angeles, California, USA). ${ }^{33}$ The sociodemographic characteristics of the participants were analysed descriptively and presented as mean $( \pm \mathrm{SD})$ or number (percentage $(\%)$ ) based on type of data. The demographic characteristics (age, sex, educational status, employment status and marital status) of the respondents were compared with non-respondents, using $\chi^{2}$ or Student t test.

\section{Factor analysis}

Items were subjected to exploratory factor analysis (EFA) using methods implemented in Mplus. Mplus accommodates ordered response categories by estimating interitem polychoric correlation coefficients. A robust weighted least squares estimator (WLSMV) was used. Factors were rotated using geomin rotation (oblique) ${ }^{34}$ resulting in solutions yielding increasing numbers of factors. These were examined and compared on the basis of the change in the $\chi^{2}$ goodness-of-fit test due to adding an additional factor (a non-significant $\chi^{2}$ probability indicated a good fit) and the values of fit indices. Fit indices included the root mean square error of approximation (RMSEA), comparative fit index (CFI) and Tucker-Lewis index (TLI). An RMSEA value $<0.08^{35}$ and CFI and TLI values $>0.90$ indicated a good fit of the data to the model. ${ }^{36}$ After performing the EFA on the full item set, the analysis was performed using a subset of items from which ambiguously or poorly performing items were removed for the purposes of scale development.

\section{Scale formation}

Items with factor loadings $>0.3$ were retained on the scales. Items were assigned to either subscale according to their loadings in factor analysis. If an item loaded in more than one factor, it was included on the scale with the highest loading factor.

\section{Stability of the factor structure}

To assess the robustness of the factor structure, analysis was repeated excluding all participants who had reported quitting smoking at the time of survey. The pattern of loadings was assessed in this subgroup. Formal comparison of the factor structure of the items for current smokers and ex-smokers was not feasible owing to the small number of ex-smokers. The stability of the factor structure was also assessed by including and excluding from analysis potentially ambiguous items and those that appeared to be inapplicable to some participants.

\section{Scale properties}

Total score of the scale

Scores for items in each subscale were added up to create two composite challenges scores. A higher score indicated greater challenges. Missing values were replaced with the mean of answered items for participants with $\leq 20 \%$ items missing. Participants with $>20 \%$ missing data were excluded from the analysis.

\section{Reliability}

Internal consistency was tested using Cronbach's coefficient $\alpha$. An $\alpha$ level of $\geq 0.7$ was considered acceptable. ${ }^{37}$ The item-scale partial correlations were also assessed (ie, correlations of each item with its subscale excluding this item).

\section{Construct validation}

There are two subtypes of validity that make up the construct validity: convergent validity (two measures of constructs that are supposed to be related are in fact related) and discriminant validity (concepts or measurements that are supposed to be unrelated are, in fact, unrelated). To assess construct validity, hypotheses about the associations between challenges to stopping and other variables were tested. It was hypothesised that selfefficacy $^{38}$ would be lower among those who have more challenges to quitting smoking (convergent validity). Likewise, ex-smokers were expected to have fewer challenges than current smokers (discriminant validity). Student $\mathrm{t}$ test was used to compare the factor scores between ex-smokers and current smokers and Cohen's $\mathrm{d}^{39}$ was used as an index of effect size $(\mathrm{d}=0.2$, small effect; $d=0.5$, moderate effect; $d=0.8$, large effect ).

\section{RESULTS}

\section{Sample characteristics}

A total of 437 questionnaires were sent to participants in the GIVE UP FOR GOOD study (total number of participants was 600; however, the remaining either dropped out or declined to participate in this substudy); 188 responses were received (43\% response rate). The demographic characteristics of the respondents were balanced with the non-respondents except that respondents were older $(55.0 \pm 12.8$ vs $49.1 \pm 13.6, \mathrm{p}<0.001)$. Six participants were excluded owing to considerable missing information (more than four items left unanswered). Of the remaining 182 respondents, $70.3 \%$ were current smokers. The demographic and smoking characteristics of study participants are presented in table 1 .

\section{Structure of the inventory}

The EFA on all 23 items identified two underlying factors. Although the $\chi^{2}$ goodness-of-fit test remained 
Table 1 Characteristics of participants

\begin{tabular}{|c|c|c|c|}
\hline & \multicolumn{3}{|l|}{ Number (\%) } \\
\hline & Current smoker $(n=128)$ & Ex-smoker $(n=54)$ & Overall $(n=182)$ \\
\hline Age in years mean $( \pm S D)$ & $55.7 \pm 12.7$ & $53.6 \pm 13.3$ & $55.0 \pm 12.8$ \\
\hline Male & $85(66.4)$ & $35(64.8)$ & $120(65.9)$ \\
\hline Born in Australia & $109(85.2)$ & 45 (83.3) & $154(84.6)$ \\
\hline \multicolumn{4}{|l|}{ Education } \\
\hline Primary school/no qualification & $6(4.7)$ & $1(1.9)$ & $7(3.8)$ \\
\hline Secondary school & $72(56.3)$ & $37(68.5)$ & 109 (59.9) \\
\hline Technical education & $28(21.9)$ & $8(14.8)$ & $36(19.8)$ \\
\hline University education & $22(17.2)$ & $8(14.8)$ & $30(16.5)$ \\
\hline \multicolumn{4}{|l|}{ Employment status } \\
\hline Employed full/part time & $57(44.5)$ & $27(50)$ & $84(46.2)$ \\
\hline Retired/pensioner & $42(32.8)$ & $14(25.9)$ & $56(30.8)$ \\
\hline Disabled/unable to work & $17(13.3)$ & $9(16.7)$ & $26(14.3)$ \\
\hline Unemployed/student/home duties & $12(9.4)$ & $4(7.4)$ & $16(8.8)$ \\
\hline \multicolumn{4}{|l|}{ Marital status } \\
\hline Married/de facto & $57(44.5)$ & 32 (59.3) & 89 (48.9) \\
\hline Widowed/divorced/separated & $52(40.6)$ & $10(18.5)$ & $62(34.1)$ \\
\hline Never married & $19(14.8)$ & $12(22.2)$ & $31(17.0)$ \\
\hline \multicolumn{4}{|l|}{ Average annual household income } \\
\hline \$A29 999 or less & $51(39.8)$ & $16(29.6)$ & $67(36.8)$ \\
\hline$\$ A 30000$ to $\$ A 59999$ & $22(17.2)$ & $8(14.8)$ & $30(16.5)$ \\
\hline$\$ A 60000$ or more & $23(18.0)$ & $16(29.6)$ & $39(21.4)$ \\
\hline Not disclosed & $32(25.0)$ & $14(25.9)$ & $46(25.3)$ \\
\hline \multicolumn{4}{|l|}{ Reason for hospital admission } \\
\hline Cardiovascular disorders & $26(20.3)$ & $21(38.9)$ & $47(25.8)$ \\
\hline Musculoskeletal disorders & $24(18.8)$ & $8(14.8)$ & $32(17.6)$ \\
\hline Respiratory disorders & $14(10.9)$ & $8(14.8)$ & $22(12.1)$ \\
\hline Nervous system disorders & $14(10.9)$ & $7(13.0)$ & $21(11.5$ \\
\hline Digestive system disorders & $15(11.7)$ & $2(3.7)$ & $17(9.3)$ \\
\hline Other & $35(27.3)$ & $8(14.8)$ & $43(23.6)$ \\
\hline \multicolumn{4}{|l|}{ Smoking characteristics* } \\
\hline Age smoking started, median (IQR) & $15.5(14,18)$ & $15(13.75,17)$ & $15(14,18)$ \\
\hline Number of years of smoking, median (IQR) & $40(31.25,48)$ & $38.5(26,46.25)$ & $39(29,48)$ \\
\hline At least one quit attempt in the past 12 months & $91(71.1)$ & $32(59.3)$ & $123(67.6)$ \\
\hline Lives with a smoker & $48(37.5)$ & $20(37.0)$ & $68(37.4)$ \\
\hline Have a smoker as friend & $110(85.9)$ & $46(85.2)$ & $156(85.7)$ \\
\hline Heavy smokers $\dagger(\mathrm{HSI} \geq 4)$ & $62(48.4)$ & $20(37.0)$ & $82(45.1)$ \\
\hline Motivation to give up smoking, median (IQR) $\ddagger$ & $8.5(7,10)$ & $9(8,10)$ & $9(7,10)$ \\
\hline Confidence in giving up smoking, median (IQR) & $5(2,8)$ & $6.5(5,9)$ & $5.5(3,8)$ \\
\hline Self-efficacy to quit, mean $( \pm S D) \S$ & $32.2 \pm 8.0$ & $32.7 \pm 8.4$ & $32.3 \pm 8.1$ \\
\hline \multicolumn{4}{|c|}{$\begin{array}{l}\text { “At the time of enrolment in the clinical trial. } \\
\text { †Measured using two-item Heaviness of Smoking Index (scores ranging from } 0 \text { to } 6 \text { with a score of } 3 \text { or less indicating 'light smokers' and } 4 \\
\text { or more indicating 'heavy smokers'). } \\
\text { †Measured using } 10 \text {-point visual analogue scale ( } 1 \text { being 'very low' and } 10 \text { being 'very high'). } \\
\text { §Measured using nine-item smoking self-efficacy scale (score ranging from } 9 \text { to } 45 \text {, higher scores indicated greater smoking temptation). } \\
\text { HSI, Heaviness of Smoking Index. }\end{array}$} \\
\hline
\end{tabular}

significant $(p<0.001)$, there was substantial improvement over the one-factor model. Adding an extra factor (three-factor solution) only marginally improved the model and only one item loaded substantially $(>0.5)$ on the additional factor. A scree plot of the eigenvalues also suggested a two-factor solution (see online supplementary figure S1). Moreover, the theoretical construct was also based on two factors.

Once the two-factor solution was adopted, the performance of items was examined and ambiguous and irrelevant items were removed. One item-'having doubt in the health benefits of stopping smoking'-did not load on any of the factors and was not strongly correlated with the other items in the scale. Also, the majority of participants reported this item was "not a challenge' $(79.7 \%, \mathrm{n}=145)$. Hence, it was eliminated from the final scale. Another item-'no support or encouragement at work to stop smoking'-was not completed by $14(7.7 \%)$ respondents and 'not a challenge' was noted as the response by $127(69.8 \%)$ participants, leading to its elimination from the final inventory. 
A second factor analysis was performed on the 21 items retained in the final inventory. This produced an almost identical pattern of loadings to the initial analysis (table 2). Extraction of two factors accounted for $50.7 \%$ of the total variance of the polychoric correlations between the items. Eight items loaded substantially $(>0.5)$ on factor one and one item had a modest loading $(>0.3)$. Twelve items loaded on factor two with eight substantial loadings and four modest loadings. Three items ('easy availability of cigarettes', 'fear of failing to stop smoking' and 'belief that I can stop smoking in the future if I need to') loaded modestly on both factors.

All fit indices were acceptable for the two-factor model: RMSEA $=0.062$ (90\% CI 0.050 to 0.074$)$, p close fit $($ RMSEA $\leq 0.05)=0.053$, CFI $=0.948$ and TLI $=0.935$. There was significant improvement from the singlefactor model (RMSEA $=0.102$, CFI $=0.841$, TLI $=0.824$ ). A model with three factors improved the fit only marginally (RMSEA $=0.057, \mathrm{CFI}=0.961, \mathrm{TLI}=0.946$ ).

The factor structure was stable and produced similar results when only current smokers were included in the analysis. The factors were only modestly correlated $(\mathrm{r}=0.33)$; hence, they measured different constructs of the challenges to stopping smoking.

\section{Scale properties}

The nine items of the first subscale were predominantly related to personal (physical, psychological or cognitive) aspects of quitting. Hence, the first subscale was labelled 'intrinsic factors'. The 12 items that loaded on the second subscale were predominantly related to social or environmental aspects of quitting. Hence, it was labelled 'extrinsic factors'. This two-dimensional 21-item scale was called the 'challenges to stopping smoking scale' (CSS-21).

The mean total (SD) scores of the intrinsic and extrinsic subscales were $22.89( \pm 6.85)$ and $21.25( \pm 7.26)$, respectively. The total scores of the 'intrinsic scale' ranged from 9 to 36 and the 'extrinsic scale' from 12 to 43. The scores of the 'intrinsic scale' were almost normally distributed (skewness $=-0.13$ ), whereas the extrinsic scores were positively skewed towards lower values (skewness $=0.82$ ). Only around $5 \%$ of participants obtained the lowest possible score for both scales $(3.8 \%$ for intrinsic scale and $6.0 \%$ for extrinsic scale). Likewise, only $2.2 \%$ of participants obtained the highest possible score for the 'intrinsic scale'. No participant had the highest possible score for the 'extrinsic scale'.

\section{Content validity}

Of the 17 responses obtained from 13 participants about additional challenges, 14 were regarded as variations of items already present in the CSS-21 scale. This indicated saturation of ideas and thus further confirmed the content validity. The three remaining additional

Table 2 Factor loading for the items in the two subscales of the CSS-21

\begin{tabular}{|c|c|c|c|}
\hline & & \multicolumn{2}{|c|}{$\begin{array}{l}\text { Loading on } \\
\text { factor }\end{array}$} \\
\hline \multicolumn{2}{|c|}{ Subscales and items } & 1 & 2 \\
\hline \multicolumn{4}{|c|}{ Factor 1} \\
\hline 1 & $\begin{array}{l}\text { Withdrawal symptoms (eg, depression, anxiety, restlessness, irritability, sleeplessness, craving, etc) } \\
\text { when I tried to stop smoking }\end{array}$ & $0.83^{*}$ & -0.06 \\
\hline 2 & Feeling lost without cigarettes & $0.82^{*}$ & -0.08 \\
\hline 3 & Being addicted to cigarettes & $0.77^{*}$ & 0.00 \\
\hline 4 & Having strong emotions or feelings such as anger, or feeling upset when I tried to stop smoking & $0.74^{*}$ & 0.08 \\
\hline 5 & Something stressful happened when I was trying to stop smoking & $0.66^{*}$ & 0.00 \\
\hline 6 & Thinking about never being able to smoke again after I stop smoking & $0.65^{*}$ & 0.15 \\
\hline 7 & Getting bored when I was trying to stop smoking & $0.56^{*}$ & $0.29^{*}$ \\
\hline 8 & Seeing things or people which reminded me of smoking & $0.55^{\star}$ & $0.24^{*}$ \\
\hline 9 & Easy availability of cigarettes & $0.43^{*}$ & $0.34^{\star}$ \\
\hline \multicolumn{4}{|c|}{ Factor 2} \\
\hline 10 & Difficulty in finding someone to help me to stop smoking & -0.07 & $0.92^{*}$ \\
\hline 11 & Lack of support or encouragement from health professionals to stop smoking & -0.02 & $0.75^{\star}$ \\
\hline 12 & The cost of stop-smoking medicines such as nicotine replacement therapy & 0.06 & $0.65^{\star}$ \\
\hline 13 & Fear of side effects from stop-smoking medicines & 0.16 & $0.63^{*}$ \\
\hline 14 & Lack of encouragement or help from family or friends to stop smoking & 0.13 & $0.61^{*}$ \\
\hline 15 & Fear of weight gain if I stopped smoking & -0.06 & $0.55^{\star}$ \\
\hline 16 & Family members or friends encouraging me to smoke & -0.02 & $0.53^{*}$ \\
\hline 17 & Fear of failing to stop smoking & $0.49^{*}$ & $0.51^{*}$ \\
\hline 18 & Belief that medicines to stop smoking do not work & $0.22^{*}$ & $0.48^{*}$ \\
\hline 19 & Fear that stopping smoking may interrupt social relationships & $0.30^{*}$ & $0.46^{*}$ \\
\hline 20 & Belief that I can stop smoking in the future, if I need to & $0.36^{*}$ & $0.44^{*}$ \\
\hline 21 & Use of other substances such as cannabis, alcohol, etc & 0.09 & $0.37^{*}$ \\
\hline
\end{tabular}


challenges ('health problems', 'personal worries' and 'lonesome') may require further investigation.

\section{Reliability}

The item and scale characteristics are presented in table 3. Cronbach's $\alpha$ for the intrinsic and extrinsic scales were 0.86 and 0.82 , respectively. Item-scale correlations were high except for one item in the 'extrinsic scale' which was nevertheless retained to preserve content validity.

\section{Construct validity}

Intrinsic and extrinsic scales were negatively correlated with the self-efficacy score $(\mathrm{r}=-0.42, \mathrm{p}<0.001$ and -0.25 , $\mathrm{p}=0.013$ ). Also, compared with ex-smokers, current smokers had a higher mean score for intrinsic $(24.0 \pm 6.4$ vs $20.5 \pm 7.4, \mathrm{p}=0.002)$ and extrinsic $(22.3 \pm 7.5$ vs $18.6 \pm 6.0$, $\mathrm{p}=0.001)$ scales. The magnitude of the difference in the means was modest for intrinsic (mean difference 3.5, 95\% CI 1.3 to 5.6, Cohen"s d 0.49) and extrinsic (mean difference $3.7,95 \%$ CI 1.4 to 6.0 , Cohen"s d 0.57) scales.

\section{DISCUSSION}

A self-administered tool for measuring challenges to stopping smoking-the CSS-21 scale-was developed and evaluated. The item pool was generated from literature, expert opinion and interviews with smokers and ex-smokers. The final CSS scale contained 21 items that measured two dimensions of challenges: intrinsic and extrinsic factors. The CSS-21 scale has content and construct validity, was stable in various analyses, has high internal consistency and a sound factorial structure. All fit indices were acceptable and the two factors were meaningful and interpretable.

Two meaningful subscales were found within the larger CSS construct. Theoretically, they reflect different types of challenges: 'intrinsic scale'-personal factors and 'extrinsic scale'-environmental factors. Most of the items were loaded as originally categorised based on the theoretical model. However, three items that were loaded on more than one factor may need reconsideration. The item 'easy availability of cigarette' was originally proposed to be part of the extrinsic subscale but loaded highly on the 'intrinsic scale'. Likewise, items such as 'fear of failing to stop smoking' and 'belief that I can stop smoking in the future, if I need to' were originally proposed as a part of intrinsic subscale but loaded highly on the 'extrinsic scale'.

Predictably, the intrinsic subscale was correlated with self-efficacy such that those with greater intrinsic challenges reported lower self-efficacy. The extrinsic subscale was not correlated with self-efficacy, which was conceptually logical as self-efficacy is an internal belief and may not be necessarily related to the external environment. The differential analysis of ex-smokers and current smokers also confirmed the validity of construct.

The CSS-21 scale has potential use in clinical practice and research. It is easy to administer, can be completed and scored quickly (approximately $5 \mathrm{~min}$ to complete)

Table 3 Item and scale characteristics

\begin{tabular}{|c|c|c|c|}
\hline \multicolumn{2}{|c|}{ Subscales and abbreviated items } & Mean $\pm S D^{*}$ & $\begin{array}{l}\text { Item-total } \\
\text { correlation }\end{array}$ \\
\hline \multicolumn{4}{|c|}{ Intrinsic factors $(n=181)$} \\
\hline 1 & Withdrawal symptoms & $2.77 \pm 1.03$ & 0.64 \\
\hline 2 & Feeling lost without cigarettes & $2.60 \pm 1.05$ & 0.66 \\
\hline 3 & Being addicted to cigarettes & $3.09 \pm 1.06$ & 0.59 \\
\hline 4 & Having strong emotions or feelings & $2.46 \pm 1.07$ & 0.64 \\
\hline 5 & Something stressful happened & $2.66 \pm 1.17$ & 0.57 \\
\hline 6 & Thinking about never being able to smoke again & $2.10 \pm 1.08$ & 0.59 \\
\hline 7 & Getting bored & $2.46 \pm 1.12$ & 0.60 \\
\hline 8 & Seeing things/people which reminded me of smoking & $2.37 \pm 1.15$ & 0.56 \\
\hline 9 & Easy availability of cigarettes & $2.38 \pm 1.27$ & 0.46 \\
\hline \multicolumn{4}{|c|}{ Extrinsic factors $(n=178)$} \\
\hline 10 & Difficulty in finding someone to help me to stop smoking & $1.65 \pm 1.03$ & 0.66 \\
\hline 11 & Lack of support from health professionals to stop smoking & $1.56 \pm 0.94$ & 0.48 \\
\hline 12 & The cost of stop-smoking medicines & $1.85 \pm 1.19$ & 0.53 \\
\hline 13 & Fear of side effects from stop-smoking medicines & $1.61 \pm 0.94$ & 0.56 \\
\hline 14 & Lack of encouragement from family or friends to stop smoking & $1.76 \pm 1.00$ & 0.49 \\
\hline 15 & Fear of weight gain if I stopped smoking & $2.03 \pm 1.15$ & 0.38 \\
\hline 16 & Family members or friends encouraging me to smoke & $1.37 \pm 0.81$ & 0.33 \\
\hline 17 & Fear of failing to stop smoking & $2.38 \pm 1.19$ & 0.60 \\
\hline 18 & Belief that medicines to stop smoking do not work & $1.81 \pm 1.04$ & 0.49 \\
\hline 19 & Fear that stopping smoking may interrupt social relationships & $1.58 \pm 0.95$ & 0.43 \\
\hline 20 & Belief that I can stop smoking in the future if I need to & $2.08 \pm 1.13$ & 0.47 \\
\hline 21 & Use of other substances such as cannabis, alcohol, etc & $1.54 \pm 0.98$ & 0.27 \\
\hline
\end{tabular}


by the patient or clinician and is easily interpretable. The clinical utility of individual items in the CSS-21 scale needs to be explored in future studies. However, the CSS-21 scale could potentially be used to identify challenges smokers have experienced during their previous quit attempts. Responses to the CSS-21 scale could also be used to develop an individualised approach in facilitating smoking cessation and to reduce the chance of relapse. Items rated as 'moderate' or 'major' challenges may warrant special attention as these may become the basis for relapse. The CSS-21 scale is suitable to assess changes in challenges over time, to develop tailored interventions or to determine the effect of interventions on various challenges.

The CSS-21 scale possesses several advantages over the existing tool $^{24}$ for identifying challenges to stopping smoking. The CSS-21 scale comprises a comprehensive list of current barriers relevant to today's smokers. It includes beliefs and views about smoking cessation medications and treatments, and challenges associated with obtaining support. This is particularly important as many smoking cessation aids are now available. ${ }^{29}$ This scale also incorporates other potential areas identified in current literature such as smoking for stress management, easy availability of cigarettes, interrupting social relationships and fear of weight gain. A number of items in the BCS were rephrased for clarity. Ambiguity was minimised by removing the 'not applicable' option of the BCS scale, which many of our participants confused with 'not a challenge'.

The study has some limitations. The participants were recruited from a smoking cessation trial for hospitalised smokers which largely included motivated smokers. Involvement in a smoking cessation trial may have affected participants' perceptions of barriers to stopping smoking. Even though participants were recruited 12 months after their index hospitalisation, the sample may not represent a general community sample. Further evaluation with smokers from other settings is warranted. Also, many of the participants were admitted for cardiorespiratory disorders for which smoking is a major risk factor, which might have influenced their answers to the questionnaire. While the sample size was acceptable for the type of analyses undertaken, the response rate was only modest, which may also limit the wider applicability of the scale. Further studies with larger samples are needed to explore the usefulness of the subscales. Additionally, the scale requires further evaluation including test-retest reliability and predictive validity in a range of contexts. Finally, no direct comparison between CSS-21 and BCS scales was made to avoid replication of similar items within the same questionnaire and to minimise missing data due to inclusion of irrelevant and/or ambiguous items from BCS.

To conclude, the CSS-21 scale provides a robust, selfadministered or interviewer-administered tool to measure challenges associated with quitting smoking. Given that it is based on current evidence, has strong psychometric properties and is brief, the CSS-21 scale offers significant promise for application in clinical practice and research.

Author affiliations

${ }^{1}$ Centre for Medicine Use and Safety, Monash University, Melbourne, Victoria, Australia

${ }^{2}$ Centre for Youth Mental Health, The University of Melbourne, Melbourne, Victoria, Australia

${ }^{3}$ School of Medicine and Public Health, University of Newcastle, Callaghan, New South Wales, Australia

${ }^{4}$ Department of Epidemiology and Preventive Medicine, Monash University, Melbourne, Victoria, Australia

${ }^{5}$ Pharmacy Department, Austin Health, Melbourne, Victoria, Australia

${ }^{6}$ Pharmacy Department, The Alfred, Melbourne, Victoria, Australia

${ }^{7}$ Pharmacy Department, Barwon Health, Geelong, Victoria, Australia

Acknowledgements The authors thank all the study participants. The authors also thank Salma Attie, Sue Baulch, Emma Dean, Loan Huynh, Marissa Izzard Josephine McGuiness and Hala Merola for their assistance in validation and survey conduct.

Contributors DT and JG conceived the idea. DT, JG, AJM, BB, MJA, ST, SGP, GRW and MJD contributed to the design and conduct of the study. DT and AJM carried out the analysis. All authors contributed in interpreting the data and critically revising the manuscript, and provided approval of the final manuscript.

Funding The clinical trial from which the study sample was drawn was supported by the Australian Research Council through the Linkage Scheme (LP110200724) with The Alfred, Austin Health and Barwon Health as partner organisations, and an investigator-initiated research (IIR) grant from Pfizer. BB is supported by an NHMRC Career Development Fellowship (1063206) and a Gladys M Brawn Career Development Fellowship from the Faculty of Health and Medicine, University of Newcastle.

Competing interests JG, MJA and BB hold an IIR grant from Boehringer Ingelheim. MJA has undertaken an unrelated consultancy for AstraZeneca. He received an honorarium for speaking at a Novartis Respiratory Symposium, assistance with attendance at the European Respiratory Society Congress from Boehringer Ingelheim and the World Health Summit from Sanofi.

Ethics approval The study was approved by the Human Research Ethics Committees of all three participating hospitals (The Alfred Human Research Ethics Committee, Austin Health Human Research Ethics Committee and Barwon Health Human Research Ethics Committee) and Monash University (Monash University Human Research Ethics Committee)

Provenance and peer review Not commissioned; externally peer reviewed.

Data sharing statement No additional data are available.

Open Access This is an Open Access article distributed in accordance with the Creative Commons Attribution Non Commercial (CC BY-NC 4.0) license, which permits others to distribute, remix, adapt, build upon this work noncommercially, and license their derivative works on different terms, provided the original work is properly cited and the use is non-commercial. See: http:// creativecommons.org/licenses/by-nc/4.0/

\section{REFERENCES}

1. U.S. Department of Health and Human Services. The health consequences of smoking-50 years of progress: a report of the surgeon general. Atlanta, GA: Department of Health and Human Services, Centers for Disease Control and Prevention, National Center for Chronic Disease Prevention and Health Promotion, Office on Smoking and Health, 2014.

2. Doll $\mathrm{R}$, Peto $\mathrm{R}$, Boreham J, et al. Mortality in relation to smoking: 50 years' observations on Male British doctors. BMJ 2004;328:1519.

3. Centers for Disease Control and Prevention. Quitting smoking among adults-United States, 2001-2010. Morbidity and mortality weekly report. U.S. Centers for Disease Control, 2011:1513-19.

4. World Health Organisation. WHO report on the global tobacco epidemic, 2011: warning about the dangers of tobacco. World Health Organisation, 2011. 
5. Australian Institute of Health and Welfare. National Drug Strategy Household Survey detailed report 2013. Canberra: Australian Institute of Health and Welfare, 2014.

6. Health and Social Care Information Centre. Statistics on smoking: England 2014. Health and Social Care Information Centre, 2014.

7. Bernstein SL, Yu S, Post LA, et al. Undertreatment of tobacco use relative to other chronic conditions. Am J Public Health 2013;103: e59-65.

8. Shiffman S, Brockwell SE, Pillitteri JL, et al. Use of smoking-cessation treatments in the United States. Am J Prev Med 2008;34:102-11.

9. Hughes JR, Keely J, Naud S. Shape of the relapse curve and long-term abstinence among untreated smokers. Addiction 2004;99:29-38.

10. Stead LF, Lancaster T. Combined pharmacotherapy and behavioura interventions for smoking cessation. Cochrane Database Syst Rev 2012;10:CD008286.

11. Gould GS. Patient-centred tobacco management. Drug Alcohol Rev 2014;33:93-8.

12. Bandura A. Social foundations of thought and action: a social cognitive theory. Englewood Cliffs, NJ: Prentice-Hall, 1986.

13. Bandura A. Self-efficacy: the exercise of control. New York: W.H. Freeman, 1997

14. Hauck Y, Ronchi F, Lourey B, et al. Challenges and enablers to smoking cessation for young pregnant Australian women: a qualitative study. Birth 2013;40:202-8.

15. Gregor K, Borrelli B. Barriers to quitting smoking among medically ill smokers. J Behav Med 2012;35:484-91.

16. Gierisch JM, Straits-Tröster K, Calhoun PS, et al. Tobacco use among Iraq- and Afghanistan-era veterans: a qualitative study of barriers, facilitators, and treatment preferences. Prev Chronic Dis 2012;9:E58.

17. Carter-Pokras OD, Feldman $\mathrm{RH}$, Kanamori $\mathrm{M}$, et al. Barriers and facilitators to smoking cessation among Latino adults. J Natl Med Assoc 2011;103:423-31.

18. Guirguis $A B$, Ray SM, Zingone MM, et al. Smoking cessation: barriers to success and readiness to change. Tenn Med 2010;103:45-9.

19. Ingall G, Cropley M. Exploring the barriers of quitting smoking during pregnancy: a systematic review of qualitative studies. Women Birth 2010;23:45-52.

20. Berg CJ, Park ER, Chang Y, et al. Is concern about post-cessation weight gain a barrier to smoking cessation among pregnant women? Nicotine Tob Res 2008;10:1159-63.

21. Twyman L, Bonevski B, Paul C, et al. Perceived barriers to smoking cessation in selected vulnerable groups: a systematic review of the qualitative and quantitative literature. BMJ Open 2014;4: e006414.
22. Rosenthal L, Carroll-Scott A, Earnshaw VA, et al. Targeting cessation: understanding barriers and motivations to quitting among urban adult daily tobacco smokers. Addict Behav 2013;38:1639-42.

23. Wendy T, Stevens SS, Michael CF. Barriers to quitting smoking. UW Center for Tobacco Research and Intervention, 2005.

24. Macnee CL, Talsma A. Development and testing of the barriers to cessation scale. Nurs Res 1995;44:214-19.

25. Asher MK, Martin RA, Rohsenow DJ, et al. Perceived barriers to quitting smoking among alcohol dependent patients in treatment. $J$ Subst Abuse Treat 2003;24:169-74.

26. Dickens G, Stubbs J, Popham R, et al. Smoking in a forensic psychiatric service: a survey of inpatients' views. J Psychiatr Ment Health Nurs 2005;12:672-8.

27. Price $\mathrm{JH}$, Everett SA. Perceptions of lung cancer and smoking in an economically disadvantaged population. J Community Health 1994;19:361-75.

28. World Health Organisation. WHO Report on the Global Tobacco Epidemic: Warning about the dangers of tobacco. Geneva: World Health Organisation, 2013.

29. Fiore MC, Jane CR, Baker TB, et al. Treating tobacco use and dependence: 2008 update. Clinical practice guideline. Rockville, MD, USA: Department of Health and Human Services. Public Health Service, 2008

30. McKee SA, O'Malley SS, Salovey P, et al. Perceived risks and benefits of smoking cessation: gender-specific predictors of motivation and treatment outcome. Addict Behav 2005;30:423-35.

31. Hendricks PS, Wood SB, Baker MR, et al. The Smoking Abstinence Questionnaire: measurement of smokers' abstinence-related expectancies. Addiction 2011;106:716-28.

32. Thomas D, Abramson MJ, Bonevski B, et al. A pharmacist-led system-change smoking cessation intervention for smokers admitted to Australian public hospitals (GIVE UP FOR GOOD): study protocol for a randomised controlled trial. Trials 2013;14:148.

33. Muthén LK, Muthén BO. Mplus user's guide. 7th edn. Los Angeles: Muthén \& Muthén, CA, 2010.

34. Browne MW. An overview of analytic rotation in exploratory factor analysis. Multivariate Behav Res 2001;36:111-50.

35. Browne MW, Cudeck R. Alternative ways of assessing model fit. Sociol Methods Res 1992;21:230-58.

36. Hu Lt, Bentler PM. Cutoff criteria for fit indexes in covariance structure analysis: conventional criteria versus new alternatives. Struct Equ Modeling 1999;6:1-55.

37. Nunnally JC, Bernstein IH. Psychometric theory. 3rd edn. New York: MvGraw-Hill, 1994.

38. Velicer WF, DiClemente CC, Rossi JS, et al. Relapse situations and self-efficacy: an integrative model. Addict Behav 1990;15:271-83.

39. Cohen JW. Statistical power analysis for the behavioral sciences. 2nd edn. Hillsdale, NJ: Lawrence Erlbaum Associates, 1988. 